\title{
Treatment Selection for Early to Intermediate Hepatocellular Carcinoma
}

\author{
Kazuhiro Nouso ${ }^{1, *}{ }^{\circledR}$, Takamasa Ohki ${ }^{2}$, Tatsuya Yamashita ${ }^{3}$ (D) Haruyuki Takaki ${ }^{4}$, \\ Chien-Au Liu ${ }^{5}$, Tae Wook Kang ${ }^{6}$, Dong Ho Lee ${ }^{7}$, So Jung Lee ${ }^{8}$, Suyash Kulkarni ${ }^{9}$, \\ Deepa Shree ${ }^{10}$ and Masatoshi Tanaka ${ }^{11}$

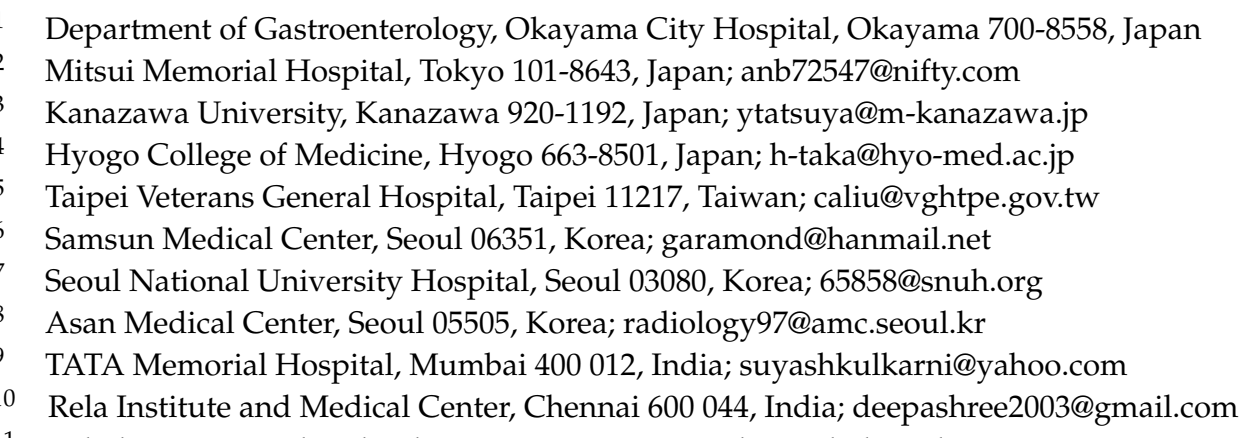

Received: 29 May 2020; Accepted: 29 June 2020; Published: 3 July 2020

\begin{abstract}
Many guidelines and standard therapies have been published for the treatment of hepatocellular carcinoma (HCC). Multiple options for the treatment of early to intermediate-stage HCC have resulted in several differences between the guidelines. In addition, more than a few non-standard therapies have been used in a real-world clinical setting. Radiofrequency ablation or chemotherapy, including hepatic arterial infusion chemotherapy and molecular target agents, are sometimes selected for the treatment of intermediate HCC, whereas in many guidelines, the recommended therapy for these patients is transcatheter arterial chemoembolization. The present status of these topics is reviewed and summarized.
\end{abstract}

Keywords: hepatocellular carcinoma; treatments; radiofrequency ablation; molecular target agents; hepatic arterial infusion chemotherapy

\section{Introduction}

Hepatocellular carcinoma (HCC) is one of the most important medical problems worldwide [1]. Hepatitis B and C virus infections are well known as major causes of HCC. Although the development of direct-acting antivirals and nucleoside analogs can eradicate or suppress hepatitis virus infections and the number of hepatitis virus-related HCC cases has decreased, HCC still occurs in patients with hepatitis. In addition, the increase of non-viral HCC caused by alcoholic liver disease and non-alcoholic steatohepatitis has become another problem [2]. According to the increasing knowledge of risk factors and the prevalence of surveillance systems, the number of HCC cases detected at an early stage has increased [3]. Patients in whom HCC is detected early are candidates for curative treatments, such as surgery or radiofrequency ablation (RFA).

There are several guidelines for the treatment of HCC [4-11]. All guidelines use background liver function and the extent of tumor progression for selection of the recommended treatments, many of which have been created based on evidence confirmed by multiple studies. Meanwhile, many new treatment modalities and applications have been adopted in real-world clinical practices, 
but they have not yet been recommended in the guidelines. The option of liver transplantation for the treatment of early HCC differs among the guidelines and is controversial and difficult to perform because of a shortage of donors, especially in Asian regions. Application of RFA or chemotherapy regimens, including hepatic arterial infusion chemotherapy (HAIC) and molecular target agents (MTA), are prevalent, non-standard therapies for intermediate-stage HCC.

In this article, we focus on non-surgical treatments and attempt to elucidate the present status of and the practical strategies for the treatment of early to intermediate-stage HCC.

\section{Application of RFA in HCC Treatment Guidelines}

The most widely used criterion in the treatment HCC algorisms is Barcelona clinic liver cancer (BCLC) staging. Both the European Association for the Study of the Liver (EASL) and the American Associations for the Study of Liver Disease (AASLD) have adopted BCLC staging in their guidelines [6,9]. In both guidelines, RFA is recommended for the treatment of both very early-stage HCC (BCLC-0) and early-stage HCC (BCLC-A). Similar applications for the use of RFA are recommended in the guidelines of Japanese, Korean, Chinese, Taiwanese, and Asian Pacific associations for the study of the liver $[4,5,7,10,11]$. All these associations, except Chinese and Taiwanese, adopted the standard application criteria for RFA, namely, HCC less than or equal to $3 \mathrm{~cm}$ in diameter and limited to three nodules. Chinese and Taiwanese guidelines accepted the use of RFA for the treatment of tumors larger than $3 \mathrm{~cm}$ in diameter.

Minimally invasive RFA involves passing high-energy radio waves through a probe inserted into a tumor. The radio waves heat the tumor and destroy the tumor cells without severe deterioration of liver function [12]. Another approach, transcatheter arterial chemoembolization (TACE), involves embolization of the feeding artery of the specific tumor and is a standard therapy for intermediate HCC. Although the curability of nodules treated with RFA is higher than that in nodules treated with TACE, none of the guidelines recommend RFA for the treatment of intermediate HCC.

\section{Current Status of RFA in Asia}

The multicenter trial committee of the Asian Conference on Tumor Ablation (ACTA) examined the current status of RFA in Asia. Thirteen hospitals in five regions (China, India, Japan, Korea, and Taiwan) provided their data. The number of hospitals was not enough to represent the status of the entire nation, but each hospital in this study had enough cases of HCC treated with RFA to show the trend in each region. The study protocol complied with the ethical guidelines of the World Medical Association Declaration of Helsinki and was approved by our institutional review boards (Approval codes: Okayama University, 1908-011; Okayama City Hospital, 1-63).

No statistical difference was observed between regions. When we stratified the patients by the status of the hepatitis virus infection and BCLC stage, no difference in overall survival (OS) was observed between regions (Figure 1). This finding indicates that uniform effectiveness of RFA was achieved in the collaborative hospitals regardless of the region. However, the median size of the tumor treated with RFA differed from one region to another (Figure 2). The median tumor size reported in Korea (Asan Medical Center, Samsung Medical Center, and Seoul National University Hospital) was the smallest $(15 \mathrm{~mm})$. In addition, 99.6\% (254/255) of tumors in Korean hospitals were less than or equal to $3 \mathrm{~cm}$ in diameter. The median tumor size reported in India (TATA Memorial Centre and Rela Institute and Medical Center) was the largest $(3.6 \mathrm{~cm})$. Furthermore, $55.4 \%(31 / 56)$ of tumors in the Indian hospitals were greater than $3 \mathrm{~cm}$ in diameter. 

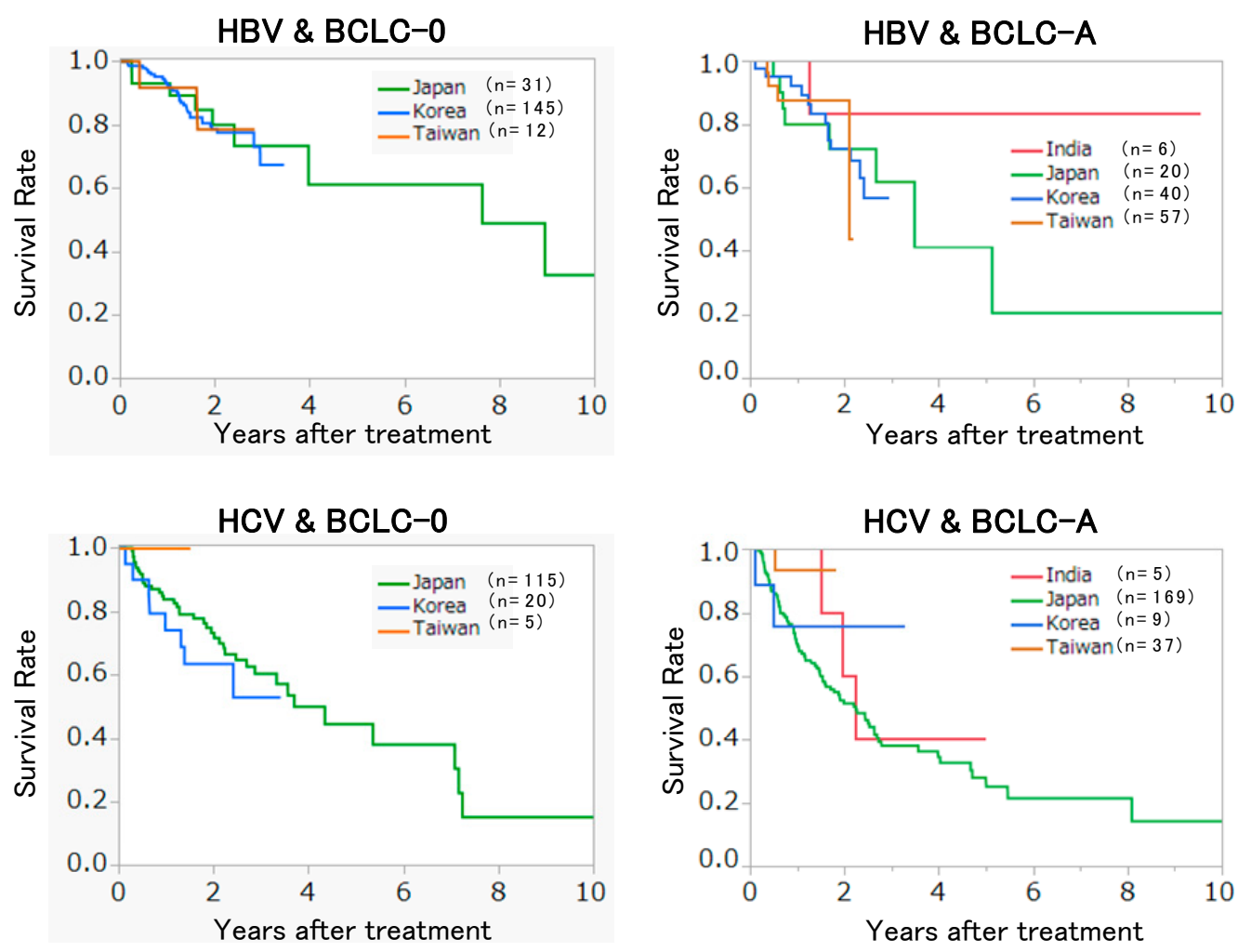

Figure 1. Recurrence-free survival of the patients in different regions.

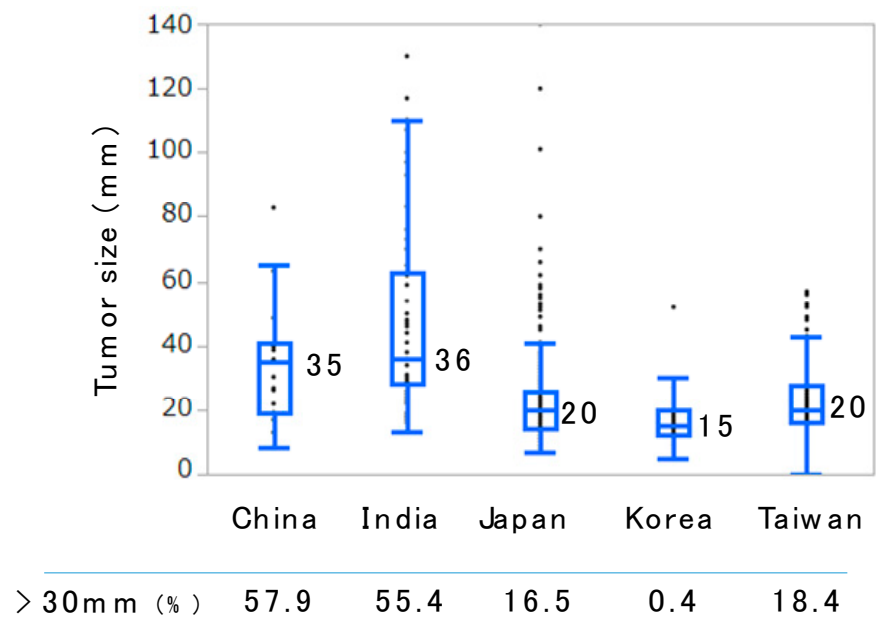

Figure 2. Box plot of the tumor size treated with radiofrequency ablation in different regions. Horizontal bars in the boxes and the numbers beside indicate median values. The numbers of patients in China, India, Japan, Korea, and Taiwan were 19, 56, 635, 255, and 185, respectively.

RFA was selected not only for the treatment of BCLC- 0 and BCLC-A patients but also for the treatment of BCLC-B and BCLC-C patients in some regions (Figure 3). The numbers of patients in China, India, Japan, Korea, and Taiwan were 19, 56, 635, 255, and 185, respectively. 


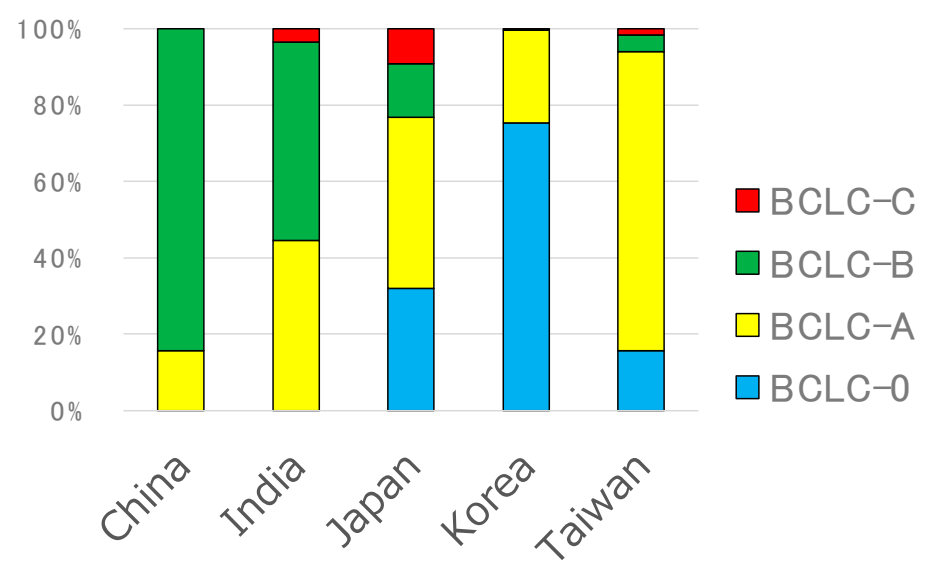

Figure 3. Barcelona clinic liver cancer (BCLC) stages of RFA-treated patients.

\section{RFA for Intermediate-Stage HCC}

RFA is not recommended for the therapy of intermediate-stage HCC. However, several patients with intermediate-stage HCC were treated with RFA in real-world clinical practices, as seen in the data of the ACTA (see the previous section). This finding indicates that many doctors think that RFA is beneficial for some patients. Although no prospective randomized trial for revealing the effectiveness of RFA has been conducted, several reports demonstrate the effectiveness of RFA for the treatment of intermediate-stage HCC [13-20] (Table 1). The application of RFA in each report was slightly different, but all the reports show the beneficial effect of RFA. Azuma et al. ablated nodules with poor lipiodol retention after TACE and reported better progression-free survival (PFS) and OS than TACE alone [16]. Yin et al. demonstrated the additive effect of RFA for the nodules that were safe to ablate [14], and Hoffman et al. reported the additive effect of RFA for patients treated with TACE using drug-eluting beads [13]. We also compared OS of intermediate-stage HCC treated with RFA and those treated with TACE after propensity score matching and demonstrated the survival benefit of RFA not only in our institute but also in other collaborative hospitals $[17,21]$. Notably, the benefit of RFA was limited to patients with BCLC-B1 and BCLC-B2. It was difficult to achieve a survival benefit in more advanced HCC cases, such as BCLC-B3 and BCLC-B4 [22].

Table 1. Radiofrequency ablation (RFA) for intermediate-stage hepatocellular carcinoma (HCC).

\begin{tabular}{|c|c|c|c|}
\hline Authors & Pt No. & Intervention & Results \\
\hline Azuma, et al. [16] & $\mathrm{n}=59$ & $\begin{array}{l}\text { TACE + RFA to the nodules } \\
\text { with poor lipiodol retention }\end{array}$ & Better PFS, OS than TACE \\
\hline Yin, et al. [14] & $\mathrm{n}=211$ & $\begin{array}{l}\text { TACE + RFA to the nodules } \\
\text { with easy to ablation }\end{array}$ & Better PFS, OS than TACE \\
\hline Hoffmann, et al. [13] & $\mathrm{n}=20$ & DC beads + RFA & Effective and Safe \\
\hline Nouso, et al. [17] & $\mathrm{n}=167$ & RFA to all nodules & Better OS than TACE \\
\hline Endo, et al. [18] & $\mathrm{n}=92$ & TACE + RFA & $\begin{array}{l}\text { Better PFS, OS than TACE } \\
\text { (especially AFP }<100 \mathrm{ng} / \mathrm{mL} \text { ) }\end{array}$ \\
\hline Kariyama, et al. [15] & $\mathrm{n}=627$ & RFA & Better OS than TACE in B1/B2 stages \\
\hline Liu, et al. [20] & $\begin{array}{c}\mathrm{n}=404 \\
(\mathrm{~B} 1 \text { stage })\end{array}$ & TACE + RFA & Better OS and PFS \\
\hline
\end{tabular}

TACE, transcatheter arterial embolization; RFA, radiofrequency ablation; DC beads, drug-eluting beads; PFS, progression-free survival; OS, overall survival.

\section{Application of Molecular Target Agents for the Treatment of Intermediate-Stage HCC}

The application of MTAs for the treatment of intermediate-stage HCC is different among guidelines. Although the efficacy of MTA for intermediate-stage HCC was demonstrated in many Phase 3 studies, including SHARP [23], REFLECT [24], and REACH-2 [25] studies, MTA is not recommended for the treatment of intermediate-stage HCC in BCLC guidelines. In many Asian guidelines, including Japanese, MTA was listed as an optional therapy $[4,5,7,11]$. This discrepancy comes from the lack of enough 
information comparing the efficacy of MTA and TACE for the treatment of intermediate-stage HCC. In addition, intermediate-stage HCC consists of a wide variety of HCC that is neither early nor advanced-stage HCC, which makes the uniform recommendation of the treatment difficult [25].

Recently, Kudo et al. showed a better survival benefit of lenvatinib than TACE in patients with intermediate-stage HCC beyond the up-to-seven criteria [26]. The report was not a prospective randomized study, but the authors used propensity scores to compensate for biases between two groups and clearly demonstrated the efficacy of lenvatinib for these patients. The PFS values of lenvatinib and TACE-treated patients were 16.0 and 3.0 months, respectively, and OS values were 37.9 and 21.3 months, respectively. These results indicate that MTA could be a treatment of choice in more advanced intermediate-stage HCC.

\section{Application of Hepatic Arterial Infusion Chemotherapy (HAIC)}

HAIC, a method that introduces anti-cancer drugs directly into the tumor-feeding artery, is traditionally used in Japan for the treatment of intermediate to advanced-stage HCC and is one of the recommended therapies in the Japanese guidelines [11]. There are no randomized controlled trials to show the effect of HAIC compared to placebo, and the objective response rates based on observatory studies vary $(0-71 \%)$ [11]. Nonetheless, doctors who are familiar with HAIC have often experienced good responses in some HCC cases.

We compared the outcome of 476 patients with HCC who underwent HAIC with 5-fluorouracil and cisplatin with that of 1466 patients who did not receive active therapy. We used the database of primary liver cancer registered by the Liver Cancer Study Group of Japan [27]. The results of the multivariate analysis, as well as propensity score-matched analysis clearly show the efficacy of HAIC. Recently, an additive effect of HAIC on sorafenib-treated patients was examined in the SILIUS RCT study [28]. The regimen of HAIC was low-dose cisplatin and fluorouracil. Although no difference in OS was observed between HAIC/sorafenib and sorafenib monotherapy, a possible survival benefit was demonstrated in patients with a tumor thrombus at a major portal vein.

In addition, HAIC is less harmful than TACE or MTA, so it can be used for patients with poor liver function [29]. Early to intermediate-stage HCC includes patients with Child-Pugh B grade. MTA cannot be used for these patients, and sometimes there is hesitation in treatment with TACE because of the fear of inducing liver failure. HAIC can be used for these patients. Concrete survival benefits of HAIC in non-advanced HCC must be proven with further examinations. Nonetheless, it is worth considering the use of less harmful HAIC at least once in patients with intermediate-stage HCC.

\section{Future Perspectives}

HCC treatment guidelines provide information about standard therapies. However, non-standard therapies sometimes have favorable results. There are many options for the treatment of early- to intermediate-stage HCC. In addition, the development of new drugs and modalities is very rapid. In particular, many MTAs have been and will continue to be developed. The choice of these drugs and the timing of changing drugs are now a matter of special interest even for intermediate-stage HCCs. Therefore, it is important to always pay attention to updated information.

Author Contributions: Writing—review and editing, K.N.; data curation, K.N., T.O., T.Y., H.T., C.-A.L., T.W.K., D.H.L., S.J.L., S.K., D.S., and M.T. All authors have read and agreed to the published version of the manuscript.

Funding: This research received no external funding.

Acknowledgments: I thank Jianjun Han, Shandong Oncology Hospital, China, and all members of the Asian Conference on Tumor Ablation (ACTA) multicenter trial committee who supported the analysis of the present status of RFA in Asia.

Conflicts of Interest: The author declares no conflict of interest. 


\section{References}

1. Ferlay, J.; Colombet, M.; Soerjomataram, I.; Mathers, C.; Parkin, D.M.; Pineros, M.; Znaor, A.; Bray, F. Estimating the global cancer incidence and mortality in 2018: GLOBOCAN sources and methods. Int. J. Cancer 2019, 144, 1941-1953. [CrossRef]

2. Tateishi, R.; Koike, K. Changing etiology of hepatocellular carcinoma. J. Gastroenterol. 2020, 55, $125-126$. [CrossRef] [PubMed]

3. Nouso, K.; Kobayashi, Y.; Nakamura, S.; Kobayashi, S.; Toshimori, J.; Kuwaki, K.; Hagihara, H.; Onishi, H.; Miyake, Y.; Ikeda, F.; et al. Evolution of prognostic factors in hepatocellular carcinoma in Japan. Aliment. Pharmacol. Ther. 2010, 31, 407-414. [CrossRef] [PubMed]

4. Omata, M.; Cheng, A.L.; Kokudo, N.; Kudo, M.; Lee, J.M.; Jia, J.; Tateishi, R.; Han, K.H.; Chawla, Y.K.; Shiina, S.; et al. Asia-Pacific clinical practice guidelines on the management of hepatocellular carcinoma: A 2017 update. Hepatol. Int. 2017, 11,317-370. [CrossRef] [PubMed]

5. Xie, D.Y.; Ren, Z.G.; Zhou, J.; Fan, J.; Gao, Q. Critical appraisal of Chinese 2017 guideline on the management of hepatocellular carcinoma. Hepatobiliary Surg. Nutr. 2017, 6, 387-396. [CrossRef] [PubMed]

6. EASL Clinical Practice Guidelines: Management of hepatocellular carcinoma. J. Hepatol. 2018, 69, $182-236$. [CrossRef] [PubMed]

7. Management consensus guideline for hepatocellular carcinoma: 2016 updated by the Taiwan Liver Cancer Association and the Gastroenterological Society of Taiwan. J. Formos. Med Assoc. 2018, 117, 381-403. [CrossRef] [PubMed]

8. Heimbach, J.K.; Kulik, L.M.; Finn, R.S.; Sirlin, C.B.; Abecassis, M.M.; Roberts, L.R.; Zhu, A.X.; Murad, M.H.; Marrero, J.A. AASLD guidelines for the treatment of hepatocellular carcinoma. Hepatology 2018, 67, 358-380. [CrossRef] [PubMed]

9. Marrero, J.A.; Kulik, L.M.; Sirlin, C.B.; Zhu, A.X.; Finn, R.S.; Abecassis, M.M.; Roberts, L.R.; Heimbach, J.K. Diagnosis, Staging, and Management of Hepatocellular Carcinoma: 2018 Practice Guidance by the American Association for the Study of Liver Diseases. Hepatology 2018, 68, 723-750. [CrossRef]

10. 2018 Korean Liver Cancer Association-National Cancer Center Korea Practice Guidelines for the Management of Hepatocellular Carcinoma. Korean J. Radiol. 2019, 20, 1042-1113. [CrossRef]

11. Kokudo, N.; Takemura, N.; Hasegawa, K.; Takayama, T.; Kubo, S.; Shimada, M.; Nagano, H.; Hatano, E.; Izumi, N.; Kaneko, S.; et al. Clinical practice guidelines for hepatocellular carcinoma: The Japan Society of Hepatology 2017 (4th JSH-HCC guidelines) 2019 update. Hepatol. Res. 2019, 49, 1109-1113. [CrossRef] [PubMed]

12. Wakuta, A.; Nouso, K.; Kariyama, K.; Nishimura, M.; Kishida, M.; Wada, N.; Mizushima, T.; Higashi, T.; Tanimoto, M. Radiofrequency ablation for the treatment of hepatocellular carcinoma with decompensated cirrhosis. Oncology 2011, 81, 39-44. [CrossRef] [PubMed]

13. Hoffmann, R.; Rempp, H.; Syha, R.; Ketelsen, D.; Pereira, P.L.; Claussen, C.D.; Clasen, S. Transarterial chemoembolization using drug eluting beads and subsequent percutaneous MR-guided radiofrequency ablation in the therapy of intermediate sized hepatocellular carcinoma. Eur. J. Radiol. 2014, 83, 1793-1798. [CrossRef] [PubMed]

14. Yin, X.; Zhang, L.; Wang, Y.H.; Zhang, B.H.; Gan, Y.H.; Ge, N.L.; Chen, Y.; Li, L.X.; Ren, Z.G. Transcatheter arterial chemoembolization combined with radiofrequency ablation delays tumor progression and prolongs overall survival in patients with intermediate (BCLC B) hepatocellular carcinoma. BMC Cancer 2014, 14, 849. [CrossRef]

15. Kariyama, K.; Wakuta, A.; Nishimura, M.; Kishida, M.; Oonishi, A.; Ohyama, A.; Nouso, K.; Kudo, M. Percutaneous Radiofrequency Ablation for Intermediate-Stage Hepatocellular Carcinoma. Oncology 2015, 89 (Suppl. 2), 19-26. [CrossRef] [PubMed]

16. Azuma, S.; Asahina, Y.; Nishimura-Sakurai, Y.; Kakinuma, S.; Kaneko, S.; Nagata, H.; Goto, F.; Ootani, S.; Kawai-Kitahata, F.; Taniguchi, M.; et al. Efficacy of additional radiofrequency ablation after transcatheter arterial chemoembolization for intermediate hepatocellular carcinoma. Hepatol. Res. 2016, 46, 312-319. [CrossRef]

17. Nouso, K.; Kariyama, K.; Nakamura, S.; Oonishi, A.; Wakuta, A.; Oyama, A.; Ako, S.; Dohi, C.; Wada, N.; Morimoto, Y.; et al. Application of radiofrequency ablation for the treatment of intermediate-stage hepatocellular carcinoma. J. Gastroenterol. Hepatol. 2017, 32, 695-700. [CrossRef] [PubMed] 
18. Endo, K.; Kuroda, H.; Oikawa, T.; Okada, Y.; Fujiwara, Y.; Abe, T.; Sato, H.; Sawara, K.; Takikawa, Y. Efficacy of combination therapy with transcatheter arterial chemoembolization and radiofrequency ablation for intermediate-stage hepatocellular carcinoma. Scand. J. Gastroenterol. 2018, 53, 1575-1583. [CrossRef] [PubMed]

19. Espinosa, W.; Liu, Y.W.; Wang, C.C.; Lin, C.C.; Wang, J.H.; Lu, S.N.; Hung, C.H. Combined resection and radiofrequency ablation versus transarterial embolization for intermediate-stage hepatocellular carcinoma: A propensity score matching study. J. Formos. Med Assoc. 2018, 117, 197-203. [CrossRef]

20. Liu, F.; Chen, M.; Mei, J.; Xu, L.; Guo, R.; Lin, X.; Zhang, Y.; Peng, Z. Transarterial Chemoembolization Combined with Radiofrequency Ablation in the Treatment of Stage B1 Intermediate Hepatocellular Carcinoma. J. Oncol. 2019, 2019, 6298502. [CrossRef]

21. Kariyama, K.; Nouso, K.; Wakuta, A.; Oonishi, A.; Toyoda, H.; Tada, T.; Hiraoka, A.; Tsuji, K.; Itobayashi, E.; Ishikawa, T; et al. Treatment of Intermediate-Stage Hepatocellular Carcinoma in Japan: Position of Curative Therapies. Liver Cancer 2020, 9, 41-49. [CrossRef] [PubMed]

22. Bolondi, L.; Burroughs, A.; Dufour, J.F.; Galle, P.R.; Mazzaferro, V.; Piscaglia, F.; Raoul, J.L.; Sangro, B. Heterogeneity of patients with intermediate (BCLC B) Hepatocellular Carcinoma: Proposal for a subclassification to facilitate treatment decisions. Semin Liver Dis. 2012, 32, 348-359. [PubMed]

23. Llovet, J.M.; Ricci, S.; Mazzaferro, V.; Hilgard, P.; Gane, E.; Blanc, J.F.; de Oliveira, A.C.; Santoro, A.; Raoul, J.L.; Forner, A.; et al. Sorafenib in advanced hepatocellular carcinoma. N. Engl. J. Med. 2008, 359, 378-390. [CrossRef]

24. Kudo, M.; Finn, R.S.; Qin, S.; Han, K.H.; Ikeda, K.; Piscaglia, F.; Baron, A.; Park, J.W.; Han, G.; Jassem, J.; et al. Lenvatinib versus sorafenib in first-line treatment of patients with unresectable hepatocellular carcinoma: A randomised phase 3 non-inferiority trial. Lancet 2018, 391, 1163-1173. [CrossRef]

25. Zhu, A.X.; Kang, Y.K.; Yen, C.J.; Finn, R.S.; Galle, P.R.; Llovet, J.M.; Assenat, E.; Brandi, G.; Pracht, M.; Lim, H.Y.; et al. Ramucirumab after sorafenib in patients with advanced hepatocellular carcinoma and increased alpha-fetoprotein concentrations (REACH-2): A randomised, double-blind, placebo-controlled, phase 3 trial. Lancet Oncol. 2019, 20, 282-296. [CrossRef]

26. Kudo, M.; Ueshima, K.; Chan, S.; Minami, T.; Chishina, H.; Aoki, T.; Takita, M.; Hagiwara, S.; Minami, Y.; Ida, H.; et al. Lenvatinib as an Initial Treatment in Patients with Intermediate-Stage Hepatocellular Carcinoma Beyond Up-To-Seven Criteria and Child-Pugh A Liver Function: A Proof-Of-Concept Study. Cancers 2019, 11, 1084. [CrossRef] [PubMed]

27. Nouso, K.; Miyahara, K.; Uchida, D.; Kuwaki, K.; Izumi, N.; Omata, M.; Ichida, T.; Kudo, M.; Ku, Y.; Kokudo, N.; et al. Effect of hepatic arterial infusion chemotherapy of 5-fluorouracil and cisplatin for advanced hepatocellular carcinoma in the Nationwide Survey of Primary Liver Cancer in Japan. Br. J. Cancer 2013, 109, 1904-1907. [CrossRef]

28. Kudo, M.; Ueshima, K.; Yokosuka, O.; Ogasawara, S.; Obi, S.; Izumi, N.; Aikata, H.; Nagano, H.; Hatano, E.; Sasaki, U.; et al. Sorafenib Plus Low-Dose Cisplatin and Fluorouracil Hepatic Arterial Infusion Chemotherapy Versus Sorafenib Alone in Patients with Advanced Hepatocellular Carcinoma (SILIUS): A Randomised, Open Label, Phase 3 Trial. Lancet Gastroenterol. Hepatol. 2018, 3, 424-432. [CrossRef]

29. Terashima, T.; Yamashita, T.; Arai, K.; Kawaguchi, K.; Kitamura, K.; Yamashita, T.; Sakai, Y.; Mizukoshi, E.; Honda, M.; Kaneko, S. Response to chemotherapy improves hepatic reserve for patients with hepatocellular carcinoma and Child-Pugh B cirrhosis. Cancer Sci. 2016, 107, 1263-1269. [CrossRef]

(C) 2020 by the authors. Licensee MDPI, Basel, Switzerland. This article is an open access article distributed under the terms and conditions of the Creative Commons Attribution (CC BY) license (http://creativecommons.org/licenses/by/4.0/). 